American J. of Engineering and Applied Sciences 3 (3): 552-559, 2010

ISSN 1941-7020

(C) 2010 Science Publications

\title{
The Influence of Modernity on Kurdish Architectural Identity
}

\author{
Salahaddin Yasin Baper and Ahmad Sanusi Hassan \\ Department of Architecture, School of Housing, Building and Planning, \\ University Sains Malaysia, Malaysia
}

\begin{abstract}
Problem statement: This study discussed the concept of identity and the role of modernity in shifting towards globalization. The literature study covered definitions of the key words which are modernity, identity and architecture. The definition included description and issues related to the key words, which became a crucial study in identifying factors which influence the concept of change and continuity in architectural identity. Approach: This study adapted a procedure of two measuring scale Syntax analysis and Semantic analysis. The study identified checklist factors which will be used as a measurable factor for the syntax analysis and prepared a proper standardized questionnaire for (Semantic analysis). The aim was to do qualitative analysis to the influence of modernity to the architectural identity throughout the history of architecture. It illustrated the level of modern influence by western and international style that bore with its unprecedented modern concepts in comparison to the accustomed norm of the traditional architecture of the region. Results: This analysis was to evaluate negative impacts on the modern architecture in relation to the local culture, religion and environment. The case study was selected areas influenced by the development of modern buildings in Erbil city, one of the ancient cities in Iraq. Conclusion: The research contribution was to measure the level of modern influence that has damaged the traditional building identity in Erbil City.
\end{abstract}

Key words: Modernity, identity, architecture, Erbil city

\section{INTRODUCTION}

In order to understand the role of modernity and its influences in shifting building identity towards a new horizon in Erbil City, this study will discuss the concept of architectural Identity focusing on the process of continuity and change as main forces between modernity and traditions in Erbil City. Architecture in the ancient city of Erbil passed through rapid transformations after the process of Iraq liberation 2003. The shared oil revenues have allowed the region to start its reconstruction and development programs much earlier than other regions. That was the result of peaceful situation, economic growth, regional and global changes. Architecture in Erbil city reflected all these layers of rapid political, economic and cultural changes. These rapid developments led to the existence of a state of chaos and confusion in the architectural forms that reflected in many cases, a strange ideological orientation forged with the specificity and privacy of the historical city.

The literature study in this study covers definitions of the key words which are modernity and architectural identity. The definition includes description and issues related to the key wards. in order to drawing up a list of variables that sets up the overall checklist factors, the concept of modernity and Identity will be investigated separately.

\section{MATERIALS AND METHODS}

Modernity definitions: Recently, Modernity has risen in new approaches and several inquiries have been perceived through critics, which conformed with the concept of new or change. Generally, the concept of modernity can be explained within three altitudes: The current, the new mode and the transient, all three of these levels of meaning refer to the characteristic importance that is ascribed to the present in the concept of modernity (Heynen, 2000). Modernity in architecture is understood in distinctive ways by a wide range of authors and critics. In this regards Stern (2009) argues that Modernism in architecture is a term that describes a "new" work which distorts all the relations and formal rules of traditional knowledge. While Berman (1994) explains modernity as a non-continuation or modification of the past. It's a new form of human selfconsciousness as a mode of power. Modernity is what

Corresponding Author: Salahaddin Yasin Baper, Department of Architecture, School of Housing, Building and Planning, University Sains Malaysia, Malaysia 
gives the present the specific quality that makes it different from the past and points the way toward the future. Modernity is also described as being a break with tradition and as typifying everything that rejects the inheritance of the past. On the other hand, Ibelings (1998) elucidates that the goal of the new modernity (Super modernism) aims to use separate programs for buildings, regardless of the time and place through the use of technology and accepting globalization in order to change, mix and, create a comfortable environment refusing cultural backgrounds.

Furthermore, modernity itself resists easy definition. Its fragmental nature on one hand and its constant search for progress and new forms on the other, would give the impression to prevent any totalizing definition. Accordingly for Whyte (2004) 'Modernity' has many meanings. It means current and actual, as opposed to past or self-intentionally new in contrast to old, whereas for Simon (2005) modernity is the period of the new. It expresses historical transformation across the range of disciplines, periods and locations by connecting the events, people and ideas of the past to construct an account of the meaning of the present. He also explains that modernity is a period of constant transformation that affects all aspects of experience from science and philosophy to urbanization and state bureaucracy life. To be modern is to be constantly confronted by the new.

The modernity is a various form phenomenon and an intellectual context full of meaning, ramping up to chase behind and looks forward to new discoveries of the worlds.

Theory: Modernization theory according to Habermas is an analysis and evaluation of modern forms of social life. Habermas explains that modernity is more than a period. It indicates the social, political, cultural and psychological conditions that arise from certain historical procedures. Modernity in this sense is related to, but distinct from, the various aesthetic works and styles that fall under the label 'modernism' (Finlayson, 2005).

On the other hand the historical analysis of Habermas's point of view indicated that, modernization directs to the release of subjects from traditional roles and values and to their expanding dependence on communication and discourse to correlate actions and formulate social order (Finlayson, 2005).

In the view of Habermas modernity is a civilized phenomenon with various forms and intellectual context in multi-meanings. It looks forward to new discoveries of new worlds. The phenomenon of modernity does not depend on the creation of crisis, because they contain many elements, but often lead to tensions and explosions that may contribute to the resolution and accelerate the transformation of all (Afaya, 1998).

Thus, modernity had multiple Faces, may be combining elements of traditional cultural elements with contemporary one, or may be re-drafting of the infrastructure of modern society, may take the form of quotation and the reasons for the current manifestations of civilization. It may also mean the process of selecting elements of other civilizations or cultures, which is different among them. Thus, the theory of modernization (Modernization theory), which refers to Habermas separates modernity from its assets and applies it as a model of social developments (Afaya, 1998).

Habermas's theory appears to rest on the absolution of validity claims to truth, lightness and actual subjectivity through discourse directed to understanding via the force of the better reason (Finlayson, 2005).

Habermas's concept about modernity could be concluded within two points. First, modernity is a project rather than a historical period and second, this project is not yet (but can and should be) executed. According to all foregoing definitions, the most prominent indicators of modernity are as follows:

- Capitalist approach

- New work distorts traditional rules

- Non-continuation with traditions

- Form phenomena

- Process of newness

- Establishing new rules

- Neglecting culture

- Multiple faces phenomenon

Technology and modernity: As stated by JeanFrancois Leotard the obligation of modernity is linked to the level of knowledge on post-industrial society, the society in which decisions are taken through a "genuine cultural technology" to rely on existing knowledge.

Continuous technical progress in science and technology and division of work introduced new dimensions to the social life and a permanent change to the customs and traditional cultures, in parallel it is resulting from political tensions and social conflicts. Hence, the modernity is not the technological and scientific revolution; it is a game to include it in the scenery of life and daily social dimension (Afaya, 1998). 
Modernity and transformation: As stated by Berman (1994), modernity is an era of continuous transformation that affects all characteristics of knowledge. Modernity is not a concept but rather a statement classification. It's a story that specifies historical transformation across the range of disciplines, periods and locations (Simon, 2005). The architectural transformation is a critical tool or a term describing the shapes and formations. It's produced within the limited time on the specific contributions of the reality. This concept has also been used to link between the form transformation and Architectural meaning as a maximum response to external and internal forces.

In this regards, Antoniades (2008) explains the existence of two types of changes: Preservation changes and destructive changes. The first leading to the stability of phenomena generation while the second cause to the emergence of new types of phenomena. On other hand Abel (1997) discusses Transformation in terms of straight adaptation to a change in climate, pursuant to an interaction between different cultural forms. One imported the other of local origins. Conclusively, it can be said that the transformation is done through human involvement to shift an element of the cultural structure. Architecture, as a culture, is one of the objectives of this change.

In this study, the definition of Modernity is described as a process of newness search for contemporary forms, which is constantly in conflict with tradition.

Finally, as a conclusion, the etymology of modern suggests that it comes from the Latin modus, meaning measure (King, 2004). In this sequence modernity can be clarified as the degree of change which the study will depend on in Syntax Analysis. Accordingly, the possible values of change can be summarized in five categories, which are:

- No change: Copying the source without any modifications

- Miner changes: Partial change of system elements

- Adaptations: Mixing the source with new elements

- Major changes: Changing the system relations

- Total changes: Altering the system rules and regulations

Architectural identity definitions: Architecture is a human product which symbolized human mentality in the past, present and his future opinion in a lively way to that human mentality identification. Furthermore, this is a historical truth which represented the distinguishing of architecture product between communities.

Carmen (2006) argues that Identity is a key concept of the modern era; it has become a common topic in the architectural discussions of the last few years. The main reasons for this obviously sudden interest for the subject were the significance of the 'after-modern' syndrome, with the crisis of modernism in architecture reinforced by the maturation effects of globalization. On the other hand, the numerous recent humanitarian studies focused on architecture as a base structure of identity through reconsideration of architecture as a fundamental means of identity. To identify the most important properties, this study will derive variables and key indicators of the concept through the study and analysis of various definitions related to Architecture.

Human basic demand: Identity is an important and essential aspect of community life; it is ranked in the list of the basic demand of the people and groups in contemporary society. Abraham developed a theory of personality that has influenced a number of different fields, including Architecture. This wide influence is due in part to the high level of practicality of Maslow's theory. This theory accurately describes many realities of personal experiences. Maslow states that people seek to overcome feelings of loneliness and alienation. This involves both giving and receiving love, affection and the sense of belonging (Simons et al., 1987).

Process of continuity: According to Castells (2004) 'cultural identity is the process by which social actor's build their own meaning according to cultural attributes. In this context, Correa (1983) explains that Identity is a process and not a found object and illustrated that identity cannot be fabricated, but may be developed according to the circumstance of culture changes.

Vocation of the place: For Abel (1997) the Concept of identity is implied as the vocation of the place. On the other hand, Jencks (1997) define identity as a place with a single feat having a special characteristic. Whereas Carmen (2006) attempts to clarify time and space as main referents of architectural identity construction. Time is related to history and thus brings genuineness to the identity construction; Space is related to geography, which grants the identity creation with an analytical spirit and appropriateness. Both approaches are founded on principles: Time exalts ideology while space favors aesthetics. One calls upon the genius of history, the other, the genius loci. Identification through time tends to convert architecture into an ideological instrument; hence the image is distinctly a construction. 
Spatial organization: Architectural identity is a group of the expressive qualities of spatial organization as well as the activities and events taking place in the area.

Form and physical expression: The concept of identity is crystallized in the architecture through the Form and its characteristics.

Identity and meaning in architecture: Meaning is a mental event that it deals first and foremost with images, ideas, concepts, thoughts and feelings. It effectively connected with the moral aspects of identity construction. Identities are the source of meaning as argued by Castells (2004) "Identity is people's source of meaning and experience". In this regards, architects have increasingly recognized the importance of symbolism and meaning in architecture and especially in building their local identity.

According to Schulz (1980) Identity does not depend on the composition and physical form of space only, but it linked to the concept of meaning in a large sense. While Jencks (1997) focuses on the role of Elements relationship in the generation of meaning, $\mathrm{He}$ argues that the differences between adjacent elements create fundamental basis for meaning.

On the other hand Colquhoun (1985) discusses that Architecture is a language with a specific set of elements already existing in the private historical sense. In the light of the above, the operational definition of architectural identity can be formulated as-Architectural Identity is a power of expression that creates differentiation integrations between multiple societies. Its values derived from its authenticity which connects man to his origins. It's an ongoing process that includes and covers cultural continuity, diversity and privacy. Thus, the physical image of identity, would take variable Frameworks across time and space, but the way of understanding the Identity meaning remains clear, according to our perception to the architectural forms. In other words, the architectural identity does not rely on the material composition and form of the building only, but also linked to the concept of the meaning which represents a significant interaction of human values with spatial characteristics.

Measuring methods: This study adapted a procedure of two measuring scale, the first is related to the visual characteristics analysis of architectural form (Table 1Syntax Analysis). The second is Semantic analysis which dealing with moral aspects of architectural Identity (Table 2). For the purpose of this study, a sample of one hundred houses was selected inside Erbil City (Fig. 1). Sample selection based on the project's importance which have been constructed after 2003 and its familiarity, in addition to its semantic richness and diversity. The methods used for data collection included: A visual characteristics analysis survey using the (syntax analysis form). In the same time, a standardized questionnaire has been prepared for (Semantic analysis), a sample of thirty architects was selected. The questionnaire contained several parts covering different enquiries including: Respondent background, vocation of a place, physical expression, identity motivation, special organization, Diversity and architectural language (meaning).
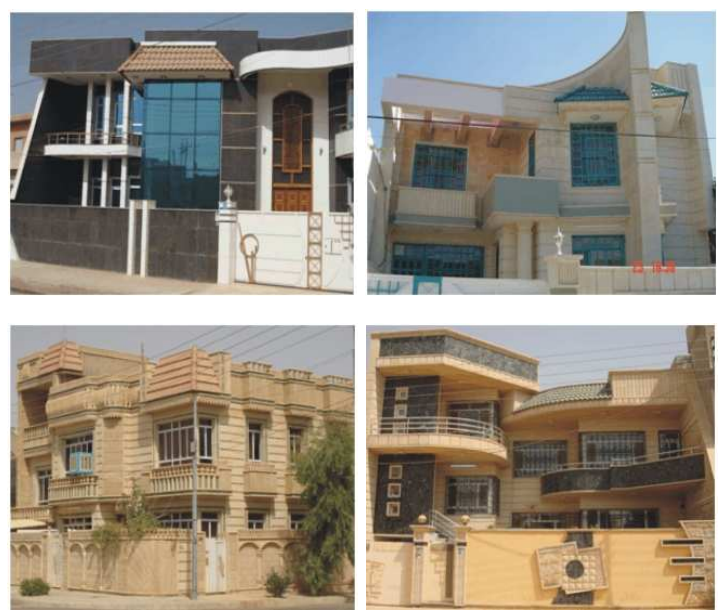

Fig. 1: Different types of houses erected after 2003 in Erbil city (source: the author)
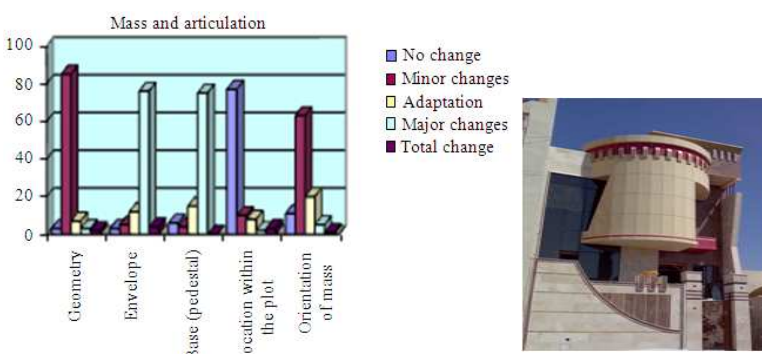

Fig. 2: The syntax analyses of building mass and articulation

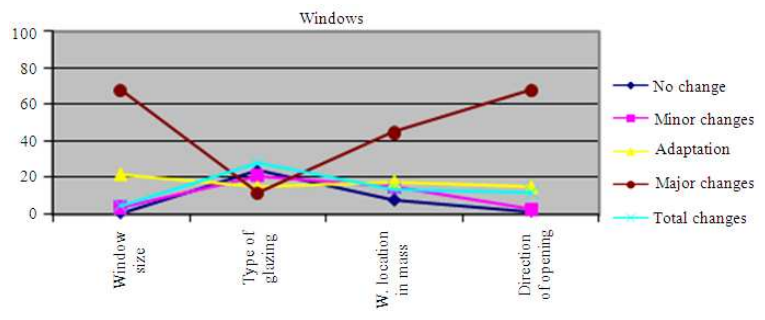

Fig. 3: The syntax analysis of building openings 
Am. J. Engg. \& Applied Sci., 3 (3): 552-559, 2010

Table 1: The syntax analysis form

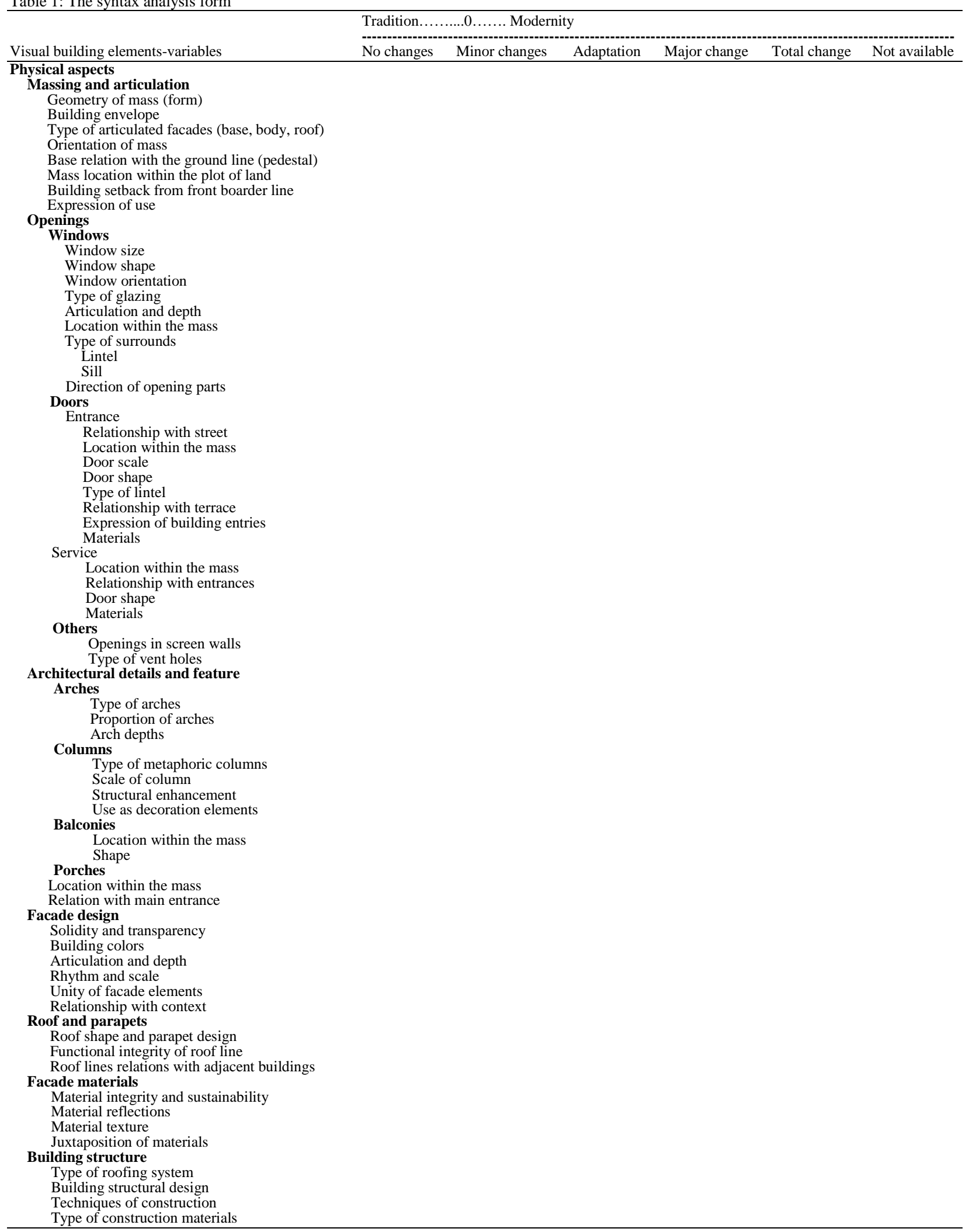


Am. J. Engg. \& Applied Sci., 3 (3): 552-559, 2010

Table 2: Yes or no answers

\begin{tabular}{llll}
\hline $\mathrm{S}$ & Questions & $\begin{array}{l}\text { Answers } \\
(\mathrm{yes})(\%)\end{array}$ & $\begin{array}{l}\text { Answers } \\
(\text { no) }(\%)\end{array}$ \\
\hline 1 & $\begin{array}{l}\text { Unity of visual elements enhance } \\
\text { architectural identity }\end{array}$ & 53.3 & 46.7 \\
2 & $\begin{array}{l}\text { Erbil city has continuity of } \\
\text { architectural identity }\end{array}$ & 36.7 & 63.3 \\
3 & $\begin{array}{l}\text { Identity is a process } \\
4\end{array}$ & 73.3 & 26.7 \\
5 & $\begin{array}{l}\text { Identity inherited from the past } \\
\text { Replicate the western theoretical } \\
\text { styles in local culture }\end{array}$ & 60.0 & 40.0 \\
\hline
\end{tabular}

\section{RESULTS}

The syntax analysis produced the following results:

\section{Mass and articulations:}

- Results show that $85 \%$ (Fig. 2) of the cases have minor changes of the geometry of mass while $76 \%$ have major changes in buildings envelope

- $75 \%$ of the cases indicate that the buildings were raised on a defined pedestal

- $\quad 77 \%$ of the cases show that there are no changes in mass location within the plot of land

- $63 \%$ Minor changes to the orientation of mass

\section{Openings:}

- About $68 \%$ of cases records major changes in the size of windows (Fig. 3). While the shape of windows are adapted normally

- About 28\% Total changes to the type of glazing in windows

- About $45 \%$ of cases indicate that the windows location within the mass dominates the overall building form

- About $65 \%$ adaptation of the entrance relationship with street

- About $76 \%$ of cases produced major changes in the scale of entrance

- The entrance location occurred an adaptation of $66 \%$ of total cases

\section{Architectural details and features:}

- Arches: 69\% adaptation of segment arches with new proportions and depth, while $23 \%$ of cases neglected the use of arches in building facades

- Columns: $18 \%$ total changes of column materials and $34 \%$ the function of use changed for structurally supported to decoration type

- Balconies: The function of balconies totally changed from environmental treatments to decoration type

- Porches: $61 \%$ of samples show that the location and size of porches adapted to new entrance scales

\section{Facade design:}

- About $83 \%$ of samples show the transparency of facades instead of solidity with more depth in elevation layers

- About $76 \%$ of building colors depending of stone cladding materials

- About $86 \%$ of samples create large scale elements

- Relationship with context partially changed as a ratio of $24 \%$

\section{Roof and parapets:}

- The selected samples show that $92 \%$ of Roof shapes remain flat and parapet design stayed as traditional

- A total of $80 \%$ of cases show the functional integrity of roof lines

\section{Facade materials:}

- The use of sustainable material reduced as a ratio of $84 \%$ (total changes)

- About $43 \%$ of samples show the unity of material texture

- About $23 \%$ of samples have total changes in the view of juxtaposition of materials, while 63\% adapted and $14 \%$ remains with minor changes

\section{Building structure:}

- The type of roofing system stayed with no changes as a total of $97 \%$ of samples

- About $75 \%$ of building structural design depending on bearing wall

- About $90 \%$ of the techniques of construction remained as its

- The construction materials have major changes of $14 \%$ of samples

On the other hand the questionnaire responses were statistically analyzed (Fig. 4). The analysis produced the following results:

- Regarding the preferable type of housing, $63.3 \%$ of the respondents agreed that the traditional house is preferable while $33.3 \%$ preferred modern houses

- As for the distinctive elements in house design, $66.7 \%$ of the respondents believed that mass and articulation is the most distinctive elements in house design. 53.3\% preferred entrance Door, $40 \%$ Architectural details, $36.7 \%$ windows, $30 \%$ roof and parapet, $63.3 \%$ Building Materials and only $10 \%$ agreed that Columns are distinctive elements 


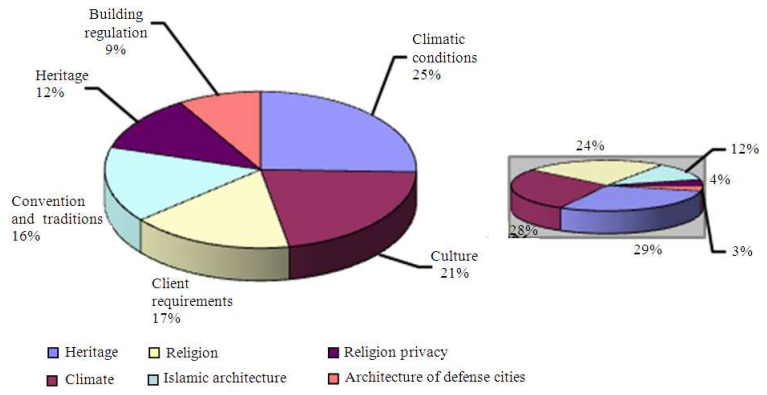

Fig. 4: The questionnaire responses analysis: (Left) sources of architectural identity; (Right) percentages of identity generation factors

- The sources of architectural identity according to the respondents was as follow: $86.7 \%$ Heritage, $80 \%$ Climate, $70 \%$ Religion, $33.3 \%$ Islamic Architecture, $13.3 \%$ region privacy and $10 \%$ architecture of defense cities

- The factors that influenced the generation of identity in architecture were perceived as: $66.7 \%$ climatic condition, $56.7 \%$ culture of society, $43.3 \%$ Client requirements, $40 \%$ convention and traditions, $30 \%$ Heritage, $23.3 \%$ Building regulations and $10 \%$ building technology

- About $75 \%$ of the respondents agreed that the architectural language related to all together factors (mass and articulation, physical elements, structural components, relationship between elements and urban context), while $23.3 \%$ agreed that the language of architecture related to physical elements, $13.3 \%$ to mass and articulation and $6.7 \%$ to urban context

- $26.7 \%$ of the correspondence estimated that the Architectural identity is related to buildings function, $36.7 \%$ symbolic features, $10 \%$ Architectural form, 3\% structure and $23.3 \%$ Aesthetics

\section{DISCUSSION}

- Architectural identity is the expression of an Object. It's a group of attributes that reflect the fundamental truth of the architectural form

- Architectural identity has two fundamental conceptualizations: The first is physical (visual Characters) related to elements and their relationships. While the second is the (Semantic) which embodies meanings that are understood through the sense analysis of architectural form

- The Internal changes happened within the structure of architectural identity through the development of its physical forms meanwhile the external changes occurred to the framework of identity, through the influence of western architectural styles

\section{CONCLUSION}

- Identity, is a series of resolutions, which are adopted by the collective society containing (ideological, social, aesthetic, economic and technical) values, these factors formed a comprehensive figure of a culture. In the case of Erbil city the research findings indicated the following conclusions:

- Variety of elements with multi layer relationships led to complex geometry

- Diversity of the elements invents various forms, which affect the urban fabric and creates visual pollution

- Raising the building via a defied pedestal as an approach towards capitalism

- Modern life criteria's neglected indoor courtyard by adding front open space, which leads to transparency in elevations

- Large scale of elements led to non-human scale of building mass

- Large glassing walls as a mode of new modernity (outside-looking/western model) were a reflection of globalization

- Using smooth materials and clear elements as a mode of new modernity

- Architectural identity of Erbil City has turned out due to the modification of physical and moral aspects of architectural compositions. These changes were the result of:

- Internal trends towards globalization

- The Contribution of foreign Architects in Erbil city reconstruction

- The reflection of the capitalist approach system

- The concept f globalization translated to modern thoughts. It affected the privacy of local communities and thus promoted the ideas of the liberation of the formal construction and adopted a method of intellectual image

- Individual needs were basically one of the justifications for changing the traditional pattern towards Western-style

- $\quad$ The change and continuity are two main forces that affect architectural identity, changing forces pushing the identity toward new horizons depending on new technologies, in the same time 
stabilization forces derive its power from traditions and conventions. These forces are matching with prince sultan's idea that "tradition is modernity's future" (Bechhoefer, 2000)

Recommendations and further researches: This study investigated the concept of modernity and its influences on architectural identity. It analyzed examples of Erbil city, developed measuring tools. Its findings explain the phenomenon of change and continuity in architectural Identity. The measuring scales which adapted by this study is useful for understanding the current trend towards achieving a cultural identity in architecture. Further research could include following issues:

- Modernization of local identity

- Language grammars as a measuring tool of identity

- Transformation in Identity (Structuralism approach)

- Architectural conventions and there influences on Architectural Identity

\section{REFERENCES}

Antoniades, A.C., 2008. The Channel of Transformation. In: Poetics of Architecture: Theory of Design, Antoniades, A.C. (Ed.). Wiley, New York, ISBN: 10: 0471285307, pp: 65-85.

Abel, C., 1997. Architecture and Identity, Towards Global Eco-Culture. 1st Edn., Avon Books, London, ISBN: 10: 0750607904, pp: 245.

Berman, A., 1994. The Configuration of Modernism. In: Preface to Modernism, Berman, A. (Ed.). University of Illions Press, USA., ISBN: 0252021037, pp: 3-27.

Afaya, M., 1998. Controversial Between Modernity and Communication. 2nd Edn., African East, Morocco, pp: 121.

Bechhoefer, W., 2000. Regional identity, tradition and modernity. Art Book, 7: 3-5. DOI: 10.1111/14678357.00183

Colquhoun, A., 1985. Essays in Architectural Criticism: Modern Architecture and Historical Change. 1st Edn., The MIT Press, Cambridge, ISBN: 13: 9780262530637, pp: 223.
Correa, C., 1983. Quest for Identity. In: Architecture and Identity, Powell, R. (Ed.). Aga Khan Award for Architecture, Singapore, pp: 10-14.

Castells, M., 2004. The Power of Identity in the Information Age: Economy, Society and Culture. 2nd Edn., Wiley-Blackwell, Oxford, ISBN: 10: 1405107138, pp: 560.

Carmen, P., 2006. Space, time: Identity. Natl. Ident., 8: 189-206. DOI: 10.1080/14608940600842060

Finlayson, G., 2005. Habermas: A Very Short Introduction. 1st Edn., Oxford University Press, USA., ISBN: 10: 0192840959, pp: 184.

Heynen, H., 2000. Architecture and Modernity: A Critique. 1st Edn., The MIT Press, USA., ISBN: 10: 0262581892, pp: 276.

Ibelings, H., 1998. Supermodernism: Architecture in the Age of Globalization. 1st Edn., NAI Publishers, USA., ISBN: 9056620746, pp: 144.

Jencks, C., 1997. Semiology and Architecture. In: Theories and Manifestoes of Contemporary Architecture, Jencks, C. and K. Kropt (Eds.). Academy Press, Great Britain, ISBN: 10: 0471976873, pp: 86-88.

King, A., 2004. Spaces of Global Cultures: Architecture Urbanism Identity. 1st Edn., Routledge, London, ISBN: 13: 9780415196208 , pp: 280.

Schulz, C., 1980. Genins IOCI-toward a phenomenology architecture. Rizzoli International Publishing Inc.

Stern, R., 2009. The Doubles of Post-Modern. In: Architecture on the Edge of Postmodernism: Collected Essay 1964-1988, Stern, R.M.A. and C. Davidson (Eds.). Yale University Press, Yale, ISBN: 13: 9780300153972, pp: 1-216.

Simons, J., D.B. Irwin and B.A. Drinnin, 1987. Psychology-The Search for Understanding. West Publishing Company, New York, ISBN: 10: 031426213X, pp: 716.

Simon, M., 2005. Modernity and Post Modernity. In: The Postmodern, Simon, M. (Ed.). Routledge, New York, ISBN: 10: 0415280648, pp: 47-51.

Whyte, I., 2004. Modernity and Architecture. In: Tracing Modernity, Manifestations of the Modern in Architecture and the City, Hvattum, M. and C. Hermansen (Eds.). Routledge, New York, ISBN: 10: 0203342410, pp: 43-44. 